\title{
Clinical Reasoning: Rapidly progressive gait disorder and cranial nerves involvement in a 9-year-old boy
}

Alexandra Lipp, MMed, Cécile Adam, MD, Jean-Philippe Brouland, MD, Mahmoud Messerer, MD, MSc, Jean-Baptiste Armengaud, MD, MSc, Sandra Asner, MD, MSc, Claudia Poloni, MD, Maja Beck-Popovic, MD, Eliane Roulet-Perez, MD, and Sébastien Lebon, MD

Neurology ${ }^{\circledR}$ 2020;94:e330-e334. doi:10.1212/WNL.0000000000008826

\section{Correspondence}

Dr. Lebon

sebastien.lebon@chuv.ch

\section{Section 1}

A previously healthy 9-year-old boy presented with a history of fatigue for 3 weeks, pain in both calves for 2 days, and a mild cough, without fever. His medical history was negative and vaccinations were up to date. Examination by his pediatrician only showed decreased deep tendon reflexes (DTR) in both lower limbs. Blood count (white blood cells [WBC] 5.4 G/L, hemoglobin $[\mathrm{Hb}] 138 \mathrm{~g} / \mathrm{L}$, thrombocytes [Tc] $251 \mathrm{G} / \mathrm{L})$, thyroid-stimulating hormone $(1.76$ $\mathrm{mU} / \mathrm{L})$, creatine kinase $(\mathrm{CK})$ level $(104 \mathrm{U} / \mathrm{L})$, and erythrocyte sedimentation rate $(3 \mathrm{~mm} / \mathrm{h})$ were all normal. Epstein-Barr virus monotest was negative and blood serology suggested a past infection.

Walking difficulties with inability to climb stairs appeared on the following days. On admission (day 1), 1 week after leg pain onset, blood pressure was $108 / 73 \mathrm{~mm} \mathrm{Hg}$ (90th percentile), heart rate $122 / \mathrm{min}$ (90th percentile), and respiratory rate $20 / \mathrm{min}$ (50th percentile). The child had no headaches. Given his young age, pain description was not possible, but it was neither paroxysmal nor triggered by touch and did not prevent sleep. Muscles were painless on palpation, there were no enlarged lymph nodes or organs, and testes were normal, as was lung auscultation. Neurologic examination showed mild proximal weakness of both upper and lower limbs (strength 4/5 Medical Research Council grade). DTR were decreased at $1+$ on upper limbs, 0 on lower limbs. Cranial nerves examination showed ptosis and limited adduction and elevation of the left eye, limited abduction of the right eye, and right facial weakness. Funduscopy was normal. There were no meningeal, pyramidal, or cerebellar signs. Abdominal and cremasteric reflexes were present and sphincter function was unaffected. Pain, temperature, proprioception, vibration, and light touch sensation were normal.

\section{Questions for consideration:}

1. What is your differential diagnosis?

2. What further testing would you propose?

\section{GO TO SECTION 2}

\footnotetext{
From the Division of Pediatrics (A.L., J.-B.A.), Pediatric Hematology Oncology Unit (C.A., M.B.-P.), Paediatric Infectious Diseases and Vaccinology Unit (S.A.), and Unit of Pediatric Neurology and Neurorehabilitation (C.P., E.R.-P., S.L.), Department Woman-Mother-Child, University Institute of Pathology (J.-P.B.), Department of Clinical Neurosciences, Service of Neurosurgery (M.M.), and Infectious Disease Service, Department of Medicine (S.A.), Lausanne University Hospital, Switzerland.

Go to Neurology.org/N for full disclosures. Funding information and disclosures deemed relevant by the authors, if any, are provided at the end of the article.
} 


\section{Section 2}

Acute onset of pain in the lower limbs followed by bilateral proximal ascending weakness, hypo/areflexia, and multiple cranial nerves palsies without impairment of consciousness point to involvement of the peripheral nervous system. Relatively elevated blood pressure and heart rate can be attributed to either pain and anxiety or involvement of autonomic fibers. A polyradiculoneuropathy (i.e., involvement of multiple nerve roots or peripheral nerves) due to Guillain-Barré syndrome (GBS) is the first and most common differential diagnosis to consider in children. Cranial nerves involvement raises the possibility of a GBS variant such as Miller Fisher syndrome (MFS) or Bickerstaff brainstem encephalitis (BBE). MFS is characterized by a triad of ophthalmoplegia, areflexia, and ataxia, but our patient was not ataxic; in BBE, impairment of consciousness and pyramidal signs are important features, which were not found. ${ }^{1}$ Polyradiculoneuropathy due to Lyme disease also has to be considered in endemic regions, even in the absence of reported history of tick bite or erythema migrans. ${ }^{2}$ Botulism was considered but usually starts by cranial nerve involvement typically with mydriasis and a descending paralysis pattern. ${ }^{3}$ Other infectious, inflammatory, toxic, or neoplastic causes can also occur but are rare. Absence of sphincter dysfunction and a normal detailed sensory examination essentially ruled out myelopathy. Symmetrical pain in the calves with gait disturbance and mild weakness can also suggest myositis, of either viral or inflammatory etiology; cranial nerves and deep tendon reflexes, however, are not affected and CK level was normal.

At this step, blood count, spinal tap, and Lyme and viral serologies were performed. Given the high level of suspicion for GBS, nerve conduction studies were not performed. However, these can be helpful for diagnosis, especially at an early stage or in atypical cases. ${ }^{4}$

Blood count showed WBC at $6.6 \mathrm{G} / \mathrm{L}$ (neutrophils $55 \%$, lymphocytes $35 \%$, monocytes $8 \%$, eosinophils $2 \%$ ); $\mathrm{Hb}$ at $135 \mathrm{~g} / \mathrm{L}, \mathrm{Tc} 267 \mathrm{G} / \mathrm{L}$, and C-reactive protein $<1 \mathrm{mg} / \mathrm{L}$ were normal. CSF opening pressure was not performed. CSF studies on day 1 revealed pleocytosis at 373 cells $/ \mathrm{mm}^{3}$ (neutrophils 55\%, lymphocytes 35\%, monocytes $8 \%$, eosinophils $2 \%$ ), a highly elevated protein level of $1,100 \mathrm{mg} / \mathrm{dL}$, and extreme decreased glucose level of $1.8 \mathrm{mg} / \mathrm{dL}$ (normal levels $45-80 \mathrm{mg} / \mathrm{dL}$ ).

On day 2, the boy became unable to stand and walk without help due to persistent calf pain. His right facial and left third paresis were more notable and abdominal and cremasteric reflexes could no longer be elicited. Sensory testing and sphincter function remained normal and plantar reflexes were in flexion. Heart rate and blood pressure were still mildly elevated.

\section{Questions for consideration:}

1. How does this change the differential diagnosis?

2. What additional testing would you perform?

\section{GO TO SECTION 3}




\section{Section 3}

Clinical symptoms were still in favor of a progressive polyradiculoneuropathy, involving multiple cranial nerves and cauda equina. White cell count in CSF above $50 / \mathrm{mm}^{3}$ together with severe hypoglycorrhachia and hyperproteinorrhachia excluded GBS and led to consideration of an infectious, inflammatory, or neoplastic etiology. A cerebrospinal MRI was performed on day 3 .

\section{Questions for consideration:}

1. What are the findings on MRI?

2. With these MRI findings, what would be the next step?

GO TO SECTION 4 


\section{Section 4}

A cerebrospinal MRI performed on day 3 revealed leptomeningeal enhancement with involvement of cerebral convexity, bilateral cranial nerves III, IV, V, VIII, and spinal cord with thickened cauda equina. Right cranial nerves VI and VII were not enhanced, which did not fully correlate with the unequivocal left third nerve, right abducens, and facial palsies. There was also a right orbitofrontal round lesion of about $18 \mathrm{~mm}$ infiltrating orbital roof and orbital gyrus with contrast enhancement (figure).

Tuberculosis (TB), neoplasm, and neurosarcoidosis were considered. ${ }^{5}$ Despite the absence of fever and weight loss and negative thoracic X-ray, antibiotic therapy for TB was started given the history of fatigue and cough and the highly suggestive CSF findings. Of note, basal meningitis compromising cranial nerves is usually reported in $\mathrm{TB}$, as in our case, but there were no nodular lesions in the brain parenchyma or signs of arteritis. ${ }^{6}$ Antibiotic therapy with isoniazid, ethambutol, rifampicin, and pyrazinamide was started on day 5 .

Neoplasia, especially lymphoma or leukemia, as well as neurosarcoidosis were simultaneously considered and searched for. HIV-1 serology was negative. Immunoglobulin electrophoresis was normal. CSF cytology was not available and given the continuing clinical deterioration, surgical resection of the supraorbital lesion was performed on day 7 in order to obtain pathologic and microbiological analyses. Pathology showed undifferentiated malignant cells and no necrotizing granuloma. Immunohistochemical study ruled out a CNS tumor, carcinoma, or melanoma. Anaplastic kinase-positive lymphoma was diagnosed via cell marker studies. CSF cytology performed on day 2 returned after the surgery and showed atypical lymphoid cells consistent with lymphoma.

A final diagnosis of primary CNS lymphoma (PCNSL) with leptomeningeal dissemination was made on day 8. Extension workup via chest-abdomen CT scan and total body PET scan showed no extraneurologic locations. The patient received combined IV and intrathecal chemotherapy (protocol NHLBFM Registry 2012). Six months after disease onset, the child was able to walk again. Neurologic examination showed complete recovery of cranial nerve impairment but mild distal weakness in both lower limbs and decreased DTR, which is also consistent with vincristine neuropathy. Last MRI 1 year after diagnosis showed mild residual leptomeningeal contrast enhancement of cauda equina and no recurrence of the right orbitofrontal lesion.

\section{Discussion}

PCNSL is a rare form of non-Hodgkin lymphoma restricted to the CNS, which usually occurs in adulthood with a male predominance. Seven percent of all PCNSL cases are limited to meninges, without parenchymal brain/spine/systemic disease. Congenital or acquired immunodeficiencies are frequent predisposing conditions. ${ }^{7}$ Our patient was HIV-1 negative, had normal blood count, and had no suggestive history of immunodeficiency.

In PCNSL with predominant meningeal involvement, as in our case, cranial nerves and lumbosacral nervous root impairment are the most frequent signs at diagnosis. ${ }^{8}$ GBS-like features are a common presentation that, with the frequent

Figure T2-weighted images

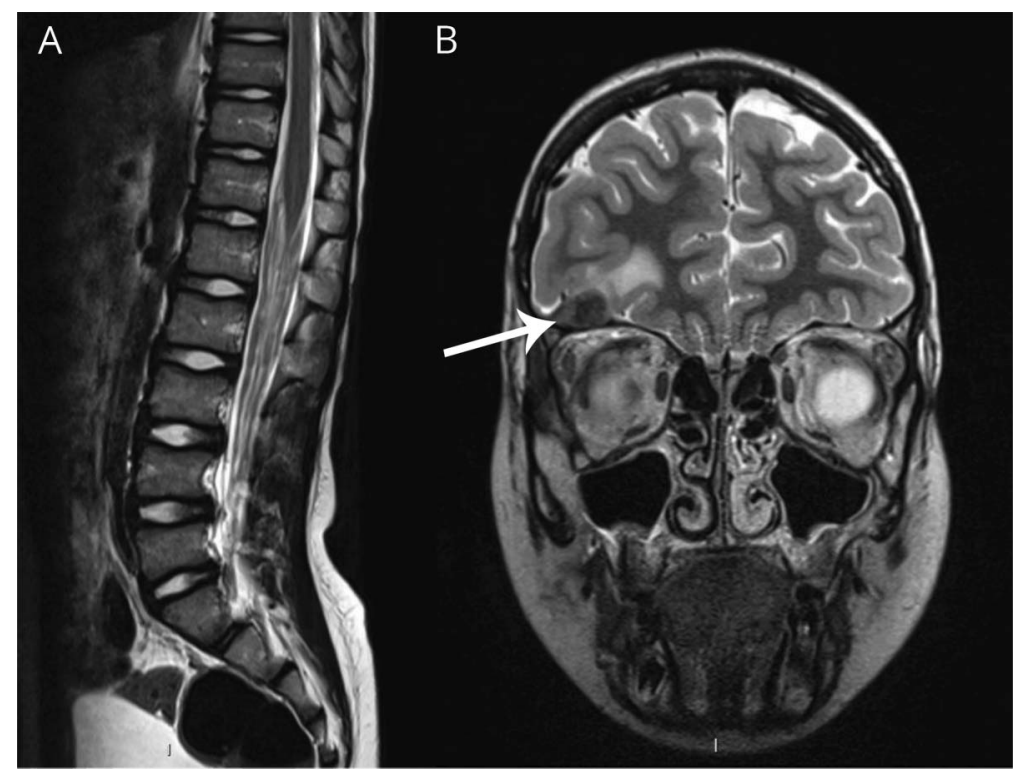

(A) Sagittal T2-weighted image of the lumbar spine shows cauda equina thickening, (B) Coronal T2-weighted image shows a right orbitofrontal lesion (arrow) with perilesional edema. 
lack of signs of systemic disease such as fever, weight loss, and night sweats, makes the diagnosis challenging, especially in children, where this condition is even rarer. ${ }^{9}$ Weakness, ataxia, headache, or seizures are presenting signs in a few cases.

Neuroimaging and CSF analysis are always abnormal. MRI typically shows leptomeningeal enhancement of the cerebral convexity, which is, after the spinal cord, the most common finding. CSF shows leukocytosis with lymphocytic predominance, moderate to highly elevated protein level (above $200 \mathrm{mg} / \mathrm{dL}$ ) in most of cases, and hypoglycorrhachia below 50 $\mathrm{mg} / \mathrm{dL}$ in more than half of cases. ${ }^{8,9}$ These CSF findings must raise the differential diagnosis of $\mathrm{TB}$, neurosarcoidosis, and neoplastic infiltration by carcinoma, lymphoma, or leukemia. 5,8,9 In TB, neurologic impairment is usually associated with symptoms such as fever, headaches, and extraneurologic involvement. ${ }^{9}$ In neurosarcoidosis, elevated protein level in CSF and hypoglycorrhachia are not so severe and pain is usually more prominent than weakness when the peripheral nervous system is involved. ${ }^{10}$ Histology is the key for the final diagnosis. Although CSF cytology and biopsy were performed in our case, due to rapid progressive worsening and atypical imaging, CSF cytology was diagnostic. CSF cytology is diagnostic in the majority of cases, whereas leptomeningeal biopsy leads to diagnosis in only one-third of cases. ${ }^{8}$ This is of importance since it can help to avoid a surgical procedure. Although very rare, lymphoma should be considered in the differential diagnosis of subacute polyradiculoneuropathy, even in healthy children.

\section{Author contributions}

A. Lipp: drafting/revising the manuscript, accepts responsibility for conduct of research and final approval. C. Adam: drafting/revising the manuscript, accepts responsibility for conduct of research and final approval. J.-P. Brouland: data acquisition, analysis or interpretation of data, accepts responsibility for conduct of research and final approval. M. Messerer: drafting/revising the manuscript, data acquisition, accepts responsibility for conduct of research and final approval, study supervision. J.-B. Armengaud: drafting/ revising the manuscript, accepts responsibility for conduct of research and final approval. S. Asner: drafting/revising the manuscript, data acquisition, analysis or interpretation of data, accepts responsibility for conduct of research and final approval, contribution of vital reagents/tools/patients. C. Poloni: drafting/revising the manuscript, data acquisition, analysis or interpretation of data, accepts responsibility for conduct of research and final approval, acquisition of data. M. Beck Popovic: data acquisition, analysis or interpretation of data, accepts responsibility for conduct of research and final approval, acquisition of data. E. Roulet-Perez: drafting/ revising the manuscript, accepts responsibility for conduct of research and final approval, study supervision. S. Lebon: drafting/revising the manuscript, data acquisition, accepts responsibility for conduct of research and final approval, acquisition of data.

\section{Study funding}

No targeted funding reported.

\section{Disclosure}

The authors report no disclosures relevant to the manuscript. Go to Neurology.org/N for full disclosures.

\section{References}

1. Sekiguchi Y, Mori M, Misawa S, et al. How often and when Fisher syndrome is overlapped by Guillain-Barre syndrome or Bickerstaff brainstem encephalitis? Eur J Neurol 2016;23:1058-1063.

2. Kumar M, Singh R, Rashid M. Lyme polyradiculitis masquerading Guillain-Barre syndrome. J Pediatr Neurosci 2016;11:384-385.

3. Griese SE, Kisselburgh HM, Bartenfeld MT, et al. Pediatric botulism and use of equine botulinum antitoxin in children: a systematic review. Clin Infect Dis 2017;66: S17-S29.

4. van den Berg B, Walgaard C, Drenthen J, Fokke C, Jacobs BC, van Doorn PA. Guillain-Barre syndrome: pathogenesis, diagnosis, treatment and prognosis. Nat Rev Neurol 2014;10:469-482.

5. Vargas TC, Thomas RL, Erickson JC. Leptomeningeal enhancement in a patient with progressive cranial neuropathies and lumbosacral radiculopathies. JAMA Neurol 2016;73:345-346.

6. Rohlwink UK, Kilborn T, Wieselthaler N, Banderker E, Zwane E, Figaji AA. Imaging features of the brain, cerebral vessels and spine in pediatric tuberculous meningitis with associated hydrocephalus. Pediatr Infect Dis J 2016;35:e301-310.

7. Thorer H, Zimmermann M, Makarova O, et al. Primary central nervous system lymphoma in children and adolescents: low relapse rate after treatment according to Non-Hodgkin-Lymphoma Berlin-Frankfurt-Munster protocols for systemic lymphoma. Haematologica 2014;99:e238-241.

8. Taylor JW, Flanagan EP, O'Neill BP, et al. Primary leptomeningeal lymphoma: International Primary CNS Lymphoma Collaborative Group report. Neurology 2013; 81:1690-1696.

9. David WS, Bowley MP, Mehan WA, Jr, Shin JH, Gerstner ER, DeWitt JC. Case 192017: a 53-year-old woman with leg numbness and weakness. N Engl J Med 2017; 376:2471-2481.

10. Burns TM, Dyck PJ, Aksamit AJ, Dyck PJ. The natural history and long-term outcome of 57 limb sarcoidosis neuropathy cases. J Neurol Sci 2006;244:77-87. 


\section{Neurology}

Clinical Reasoning: Rapidly progressive gait disorder and cranial nerves involvement in a 9-year-old boy

Alexandra Lipp, Cécile Adam, Jean-Philippe Brouland, et al.

Neurology 2020;94;e330-e334

DOI 10.1212/WNL.0000000000008826

This information is current as of January 20, 2020

\section{Updated Information \&} Services

References

Subspecialty Collections

Permissions \& Licensing

Reprints including high resolution figures, can be found at: http://n.neurology.org/content/94/3/e330.full

This article cites 10 articles, 2 of which you can access for free at: http://n.neurology.org/content/94/3/e330.full\#ref-list-1

This article, along with others on similar topics, appears in the following collection(s):

All Pediatric

http://n.neurology.org/cgi/collection/all_pediatric

Cranial neuropathy

http://n.neurology.org/cgi/collection/cranial_neuropathy

Information about reproducing this article in parts (figures,tables) or in its entirety can be found online at:

http://www.neurology.org/about/about_the_journal\#permissions

Information about ordering reprints can be found online:

http://n.neurology.org/subscribers/advertise

Neurology ${ }^{\circledR}$ is the official journal of the American Academy of Neurology. Published continuously since 1951, it is now a weekly with 48 issues per year. Copyright @ 2020 American Academy of Neurology. All rights reserved. Print ISSN: 0028-3878. Online ISSN: 1526-632X.

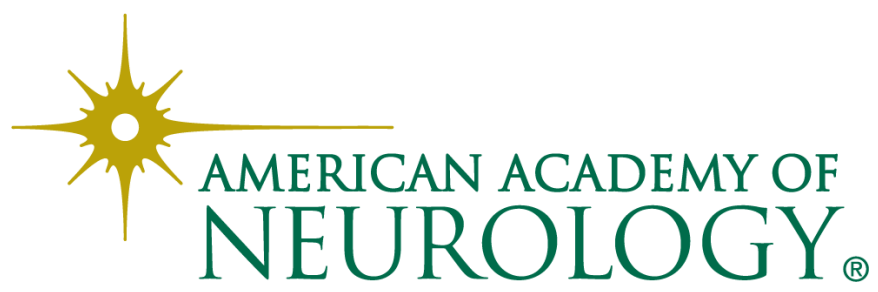

